\title{
EULAR PsA management recommendations 2019: can the recommendations be improved?
}

\author{
Roy M Fleischmann
}

The European League Against Rheumatism (EULAR) has published recommendations for the treatment of psoriatic arthritis (PsA) which have been updated twice to remain timely, responding to the rapid advances in the discovery of new compounds, effective treatment strategies and evolving information on safety. ${ }^{1-3}$ Each recommendation has been supported by a systematic literature review (SLR) which formed the basis for the recommendations. ${ }^{4-6}$ Each version has had important additions and deletions; the recommendations have been increasingly useful to many stakeholders in the rheumatology community.

The American College of Rheumatology/National Psoriasis Foundation (ACR/NPF) and the Group for Research and Assessment of Psoriasis and Psoriatic Arthritis (GRAPPA), an international network of rheumatologists, dermatologists, radiologists, geneticists, methodologists, epidemiologists and patient research partners, have also provided direction. $^{7-9}$

The strengths of the EULAR recommendations are many-fold. The recommendations have been updated to reflect new developments in treatment strategies, including efficacy and safety. Multiple experts are involved, including rheumatologists representing most European countries, patients with PsA, health professionals and a dermatologist, which allows for a wide breadth of expertise to form the recommendations. Importantly, the recommendations are based primarily on evidence from the SLR, but gives latitude for the experts to use their long-standing PsA disease experience and its treatment in developing the recommendations, not constrained by yes or no pairwise comparisons as is required by the processes used by ACR/ NPF and GRAPPA. ${ }^{10-14}$

Medicine, University of Texas Southwestern, Dallas, TX 75390, USA

Correspondence to Dr Roy M Fleischmann, Medicine, University of Texas Southwestern, Dallas, TX 75231, USA; rfleischmann@arthdocs.com
EULAR and GRAPPA use 'recommendation' rather than 'guideline', a description used by ACR/NPF. A 'recommendation' is a suggestion of the best course of action in a situation, while a 'guideline' provides broad advice in following a process but does not provide precise requirements. The difference is subtle but important; a recommendation is less restrictive compared with a guideline and provides greater flexibility.

EULAR, ACR/NPF and GRAPPA have followed different processes, with EULAR using the Oxford Centre for Evidence-Based Medicine (OCEBM) process, ACR/NPF using the Grading of Recommendations Assessment, Development and Evaluation (GRADE) process, and GRAPPA using a modification of GRADE. ${ }^{10-14}$

The different processes can, and probably do, lead to differences in the conclusions for multiple reasons: (1) OCEBM and GRADE use a different weight on expert opinion versus evidence in the case of low-quality evidence; (2) the voting panels differed with respect to the number of rheumatologists, dermatologists and patients involved; (3) the disease aspect(s) assessed; and (4) the presentation of the recommendations.

EULAR focuses primarily on nontopical, pharmacological therapies for the musculoskeletal aspects of PsA, but also addressing the spectrum of PsA to some extent. The EULAR recommendations are detailed and the reasoning explained in the same paragraph(s) and the accompanying table, including the strength of the recommendation, the level of evidence and the level of agreement among the experts. Because of these processes, a clearly defined treatment cascade can be developed in an easily understandable flow chart. GRAPPA presents their recommendations by disease domain in one grid for treatment selection and another for treatment decisions based on comorbidities. ACR/NPF used a pure GRADE process focusing on patients with 'active PsA' overall and evaluated pharmacological and non-pharmacological therapies. The application of GRADE results in pairwise comparisons and a series of individual recommendations, rather than a grid or flow chart. The ACR/NPF guideline is more convoluted and, although the recommendations are generally comparable with the other two (with a few notable exceptions based on the weight of expert opinion and the year of publication), it is a more difficult document to comprehend.

Beyond the differences in specific questions addressed, the patient population to which the recommendations apply, patients with active PsA, was mostly similar between the documents. However, the definition of active disease in the EULAR recommendations refers primarily to musculoskeletal manifestations (but not exclusively); GRAPPA considers activity in specific domains of PsA, while ACR/NPF defined active PsA based on activity in any of the features of PsA according to patient and physician attribution.

The key differences in methodologies used by each of these organisations contribute to fundamental differences in the recommendations. ${ }^{15} 16$

Despite these differences, they have followed similar general strategies: all are created by panels of 'experts' who derive their conclusions based on examination of peer-reviewed published literature and develop evidence-based guidance for clinicians and other stakeholders.

The question posed however is whether the EULAR recommendations can be even more effective with a greater global relevance.

PsA is a disease affecting multiple domains. EULAR, ACR/NPF and GRAPPA have differing approaches to addressing the treatment of different domains, when to treat with what therapy, what is important in deciding on specific therapies, and their approaches to addressing comorbidities, safety and the relative risk-benefit of available therapies. As the three documents arrive at somewhat different conclusions, with some conflicting suggestions for when to use which therapy, even though some of the same experts participated in two or more of these three panels, it is problematic for the clinical rheumatologist to know the best course of action in treating a given individual. Therefore, although a consensus document developed by all three bodies may be difficult to accomplish for multiple reasons, a joint document which merges the strengths of all should be developed. The evidence of effectiveness of a medication 
or a strategy is the evidence worldwide; it is not different in the member organisations of EULAR from elsewhere in the world. The same is true of safety, although there may be regional variations. A recommendation developed by Europeans primarily for Europeans (although not exclusively) is not as meaningful as a global consensus.

The major strength of the EULAR recommendation is that the recommendations are presented in a clear, concise, transparent manner with simple, easyto-follow flow charts; it avoids the difficulty of the ACR/NPF guideline presenting the statement in tables, then referring to numerous answers to the different Patient/Problem, Intervention, Comparison, Outcome (PICO) questions to understand the relevance of the statement, and then referring to a diagram to try to understand the flow. The EULAR format should be retained. However, the GRAPPA grids discussing different domains are very useful. It would be preferable to link the domain grid from GRAPPA to the treatment flow chart from EULAR.

The EULAR recommendation does not address safety and comorbidities as fully as the ACR/NPF guideline or the treatment of multiple domains of PsA as does GRAPPA. It would be worthwhile to combine both within the strengths of the EULAR recommendation.

The EULAR recommendation strongly endorses a treat-to-target (T2T) strategy and differentiates aggressiveness of therapy by whether the disease is polyarticular or poor prognostic markers are present. ${ }^{17}$ ACR/NPF distinguishes by degree of PsA activity. GRAPPA differentiates by domain involved. These differences lead to differences in treatment strategy. A consensus integrating these would be helpful to the rheumatology community.

The target metric for EULAR is remission (abrogation of inflammation) or low disease activity (LDA), and refers to the T2T recommendations for guidance as to the use of the Disease Activity in PSoriatic Arthrits (DAPSA), minimal disease activity (MDA) and very low disease activity (VLDA). ${ }^{17}$ ACR/NPF also advocates a T2T philosophy but fails to provide a metric to assess the goal of therapy. GRAPPA recommends an average of scores on three visual analogue scales and the DAPSA for clinical practice and remission, not defined, should be the target, with MDA/LDA/VLDA as feasible alternatives. The target should include assessment of musculoskeletal disease, skin disease and health-related quality of life. ${ }^{18}$ Thus the three are at odds with respect to key treatment goals, although there is a single consensus document in existence. ${ }^{17}$

The SLRs are a strength of the EULAR and GRAPPA recommendations and the ACR guideline as they provide detailed unbiased descriptions of what has been published in the peer-reviewed literature. The SLR needs to be carefully reviewed by the entire voting panel prior to the consensus meeting so that the strongest and highest level of evidence helps inform the opinion of the expert, rather than just the experience of the expert. The SLR performed for ACR and GRAPPA should also be published. It is important that the strength of the manuscripts and the risk of bias in the SLR are tabulated and properly addressed in the recommendations. The SLRs are at least 1 year old when finally published, missing important new information over that year. One area of improvement in the process could be that the SLRs could be published when completed, prior to the publication of the recommendations, and then updated as necessary, as was done in the EULAR PsA recommendation for the Study of Etanercept and Methotrexate in Subjects with Psoriatic Arthritis (SEAM) trial.

The voting panel may occasionally arrive at a different conclusion from the evidence presented in the SLR based on their experience. This is a prerogative of the expert panel, but in order to maintain credibility for choosing an option not supported by the evidence, the reasoning should be described comprehensively as to why the experts disagreed with the SLR.

One of the problems with 'Expert Opinion' is just that: it is opinion unless it is supported by strong evidence from welldesigned and well-conducted randomised controlled trials. The evidence can either support the opinion or it cannot. But the evidence must be accurately and clearly evaluated, meeting very high standards, which are consistent. It is difficult to accomplish this from an abstract only, which should not inform the recommendation. It is also problematic to equate the results of an open-label, poorly powered, observational efficacy trial from a registry which does not include every patient nor require the complete collection of well-validated metrics at specific and timely intervals with a well-designed, properly powered, randomised head-to-head clinical trial. The SLR should address this appropriately so that a lower level of evidence trial does not become the basis of an 'expert opinion'.

Another consideration is the strength of the evidence for a recommendation and whether this should be equally valued with expert opinion or whether it is stronger.
There are instances in the three documents where there are disparate suggestions even though all three consider the same evidence-expert opinion may take precedence over the evidence or vice versa. Such an example is the placement of Jakinibs in the treatment paradigm with the ACR/ NPF guideline suggesting its use earlier and more aggressively than the EULAR recommendation. This could also be rectified by a consensus document of all three organisations.

What is common with EULAR and ACR/NPF, but less so with GRAPPA, is an emphasis on medication cost and the difference in access to different medications globally. The result is recommending one treatment strategy over another based on cost alone, rather than the evidence. This is specifically part of the recommendation development process for EULAR and is obviously very germane. However, cost should not be the basis for determining recommendations for utilisation of different medications or strategies. The evidence of the best risk to benefit ratio for the patient should take precedence. Once the order of suggestions is established, based on highlevel evidence of safety and efficacy, then the physician/patient/payer can determine which medication can be used (rather than should be used) based on the ability of the patient to have access to the medication. It is problematic to recommend a less expensive, but less effective, medication over a more effective medication based on cost. Cost is important on a local basis and should be addressed locally rather than globally.

A $\geq 66 \%-75 \%$ minimum consensus is reasonable for the adoption of a recommendation.

In summary, the EULAR recommendations have been an important contribution to a large community involved with the treatment of patients with PsA. The document can be strengthened to have even more importance. The three most important suggestions are the following: (1) there should be one document that is agreed to globally, even if there are regional differences in following the suggestions due to comorbidities and accessibility of medications; (2) high-quality, strong evidence should prevail over 'Expert Opinion', but expert opinion is important in positioning the evidence to where it can best be used; and (3) accessibility of medications is of paramount importance, but the lack of accessibility should not diminish the evidence supporting one medication or strategy over another.

Handling editor Josef S Smolen 
Contributors RMF wrote the editorial, collected the references, revised it critically for important intellectual content and approved the final version published.

Funding The authors have not declared a specific grant for this research from any funding agency in the public, commercial or not-for-profit sectors.

Competing interests None declared.

Patient and public involvement Patients and/or the public were not involved in the design, or conduct, or reporting, or dissemination plans of this research.

Patient consent for publication Not required.

Provenance and peer review Commissioned; internally peer reviewed.

(c) Author(s) (or their employer(s)) 2020. No commercial re-use. See rights and permissions. Published by BMJ.

\section{Check for updates}

To cite Fleischmann RM. Ann Rheum Dis 2020;79:680-682

Received 19 April 2020

Revised 20 April 2020

Accepted 2 May 2020

Published Online First 30 July 2020

\section{CSLinked}

http://dx.doi.org/10.1136/annrheumdis-2020-

217159

Ann Rheum Dis 2020;79:680-682.

doi:10.1136/annrheumdis-2020-217236

ORCID iD

Roy M Fleischmann http://orcid.org/0000-0002-66301477

\section{REFERENCES}

1 Gossec L, Smolen JS, Gaujoux-Viala C, et al. European League against rheumatism recommendations for the management of psoriatic arthritis with pharmacological therapies. Ann Rheum Dis 2012;71:4-12.

2 Gossec L, Smolen JS, Ramiro S, et al. European League against rheumatism (EULAR) recommendations for the management of psoriatic arthritis with pharmacological therapies: 2015 update. Ann Rheum Dis 2016:75:499-510.

3 Gossec L, Baraliakos X, Kerschbaumer A, et al. European League against rheumatism (EULAR) recommendations for the management of psoriatic arthritis with pharmacological therapies: 2019. Ann Rheum Dis 2020;76:960-77.

4 Ash Z, Gaujoux-Viala C, Gossec L, et al. A systematic literature review of drug therapies for the treatment of psoriatic arthritis: current evidence and metaanalysis Informing the EULAR recommendations for the management of psoriatic arthritis. Ann Rheum Dis 2012:71:319-26.

5 Ramiro S, Smolen JS, Landewé R, et al. Pharmacological treatment of psoriatic arthritis: a systematic literature review for the 2015 update of the EULAR recommendations for the management of psoriatic arthritis. Ann Rheum Dis 2016;75:490-8.

6 Kerschbaumer A, Smolen JS, Dougados M, et al. Pharmacological treatment of psoriatic arthritis: a systematic literature research for the 2019 update of the EULAR recommendations for the management of psoriatic arthritis. Ann Rheum Dis.

7 Singh J, Guyatt G, Ogdie A, et al. American College of Rheumatology/National psoriasis Foundation guideline for the treatment of psoriatic arthritis. Arthritis \& Rheumatology 2018;2019:5-32.

8 Ritchlin CT, Kavanaugh A, Gladman DD, et al. Treatment recommendations for psoriatic arthritis. Ann Rheum Dis 2009;68:1387-94.
9 Coates LC, Kavanaugh A, Mease PJ, et al. Group for research and assessment of psoriasis and psoriatic arthritis 2015 treatment recommendations for psoriatic arthritis. Arthritis Rheumatol 2016:68:1060-71.

10 van der Heijde D, Aletaha D, Carmona L, et al. 2014 update of the EULAR standardised operating procedures for EULAR-endorsed recommendations. Ann Rheum Dis 2015:74:8-13.

11 Guyatt GH, Oxman AD, Vist GE, et al. Grade: an emerging consensus on rating quality of evidence and strength of recommendations. BMJ 2008;336:924-6.

12 Guyatt GH, Oxman AD, Kunz R, et al. Grade guidelines: 2. framing the question and deciding on important outcomes. J Clin Epidemiol 2011;64:395-400.

13 Andrews J, Guyatt G, Oxman AD, et al. Grade guidelines: 14. going from evidence to recommendations: the significance and presentation of recommendations. J Clin Epidemiol 2013;66:719-25.

14 Andrews JC, Schünemann HJ, Oxman AD, et al. Grade guidelines: 15. going from evidence to recommendation-determinants of a recommendation's direction and strength. J Clin Epidemio 2013;66:726-35

15 Gossec L, Coates LC, de Wit M, et al. Management of psoriatic arthritis in 2016: a comparison of EULAR and grappa recommendations. Nat Rev Rheumatol 2016;12:743-50

16 Ogdie A, Coates LC, Gladman DD. Treatment guidelines in psoriatic arthritis. Rheumatology 2020;59:i37-46.

17 Smolen JS, Schöls M, Braun J, et al. Treating axial spondyloarthritis and peripheral spondyloarthritis, especially psoriatic arthritis, to target: 2017 update of recommendations by an international Task force. Ann Rheum Dis 2018;77:3-17.

18 Coates LC, FitzGerald O, Merola JF, et al. Group for research and assessment of psoriasis and psoriatic Arthritis/Outcome measures in rheumatology consensus-based recommendations and research agenda for use of composite measures and treatment targets in psoriatic arthritis. Arthritis Rheumatol 2018:70:345-55. 


\section{Correction: EULAR recommendations for the management of psoriatic arthritis with pharmacological therapies: 2019 update}

Gossec L, Baraliakos X, Kerschbaumer A, et al. EULAR recommendations for the management of psoriatic arthritis with pharmacological therapies: 2019 update. Ann of Rheum Dis 2020;79:700.12.

The author name should be Juan D Cañete instead of JD Canete.

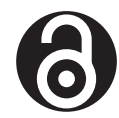

\section{OPEN ACCESS}

Open access This is an open access article distributed in accordance with the Creative Commons Attribution Non Commercial (CC BY-NC 4.0) license, which permits others to distribute, remix, adapt, build upon this work noncommercially, and license their derivative works on different terms, provided the original work is properly cited and the use is non-commercial. See: http://creativecommons.org/licenses/by-nc/4.0/.

(C) BMJ Publishing Group Limited 2020. Re-use permitted under CC BY-NC. No commercial re-use. See rights and permissions. Published by BMJ.

Ann Rheum Dis 2020;79:e139. doi:10.1136/annrheumdis-2020-217159corr1

A) Check for updates 